\title{
Evidence for Linguistic Deficit in Nonlexical Processing in Reading. A Study of a Spanish-Speaking Patient
}

\author{
Pilar Martín Plasencia, Jaime Iglesias Dorado, and Juan Manuel Serrano \\ Universidad Autónoma de Madrid, Spain
}

\begin{abstract}
Previous studies have shown that in the so-called opaque languages (those in which spelling does not correspond to pronunciation), there are relatively independent routes for lexical and nonlexical processing, that is, for words and nonwords, both in spoken and in written language. On the other hand, in the so-called transparent languages (those in which pronunciation corresponds to written forms), empirical evidence is scarcer. In this study of a neurological patient (parieto-temporal lesion), speaker of a transparent language (Spanish) showing a specific deficit in nonlexical reading processing, linguistic analysis for words was relatively preserved. This finding suggests the use of various routes in the processing of transparent languages.
\end{abstract}

Keywords: reading, nonlexical, transparent language

Estudios previos han mostrado que los llamados lenguajes opacos (en los que la ortografía no se corresponde con la pronunciación), hay rutas relativamente independientes para el procesamiento léxico y no léxico, es decir para palabras y no palabras, tanto en lengjaue hablado como escrito. Por otro lado, en los llamados lenguajes transparentes (en los que la pronunciación se corresponde con las formas escritas), hay menos evidencia empírica. En este estudio de un paciente neurológico (lesión parieto-temporal), que habla un lenguaje transparente (español), mostrando un déficit específico en el procesamiento de lectura no léxica, el análisis lingüística para las palabras estaba relativamente preservada. Este descubrimiento sugiere el uso de varias rutas en el procesamiento de los lenguajes transparentes.

Palabras clave: lectura, no léxica, lenguajes transparentes

This work was supported by Project SEJ2004-06039 from the Spanish Ministerio de Educación y Ciencia.

Correspondence concerning this articles should be addressed to: Pilar Martín Plasencia, Ciudad Universitaria de Cantoblanco, Dept. Psicología Biológica y de la Salud, Facultad de Psicología, Universidad Autónoma de Madrid, 28049-Madrid (Spain). E-Mail: pmartin@uam.es 
The differences between the so-called transparent languages (those in which written symbols correspond to a single phoneme) and opaque ones (those in which the pronunciation of a phoneme depends on the context) has led researchers to consider the possibility that individuals use different strategies - depending on their first language-for speech and reading (Ardila, 1991). Thus, some authors have postulated that in transparent languages, such as Spanish or Italian, speakers use a single route that would first demand the individual conversion of each of the phonemes making up a word, whether known or unknown. In contrast, opaque languages, such as English or French, would require at least one additional route based on lexico-semantic or lexico-visual analysis. This latter route would be used for words whose written form does not correspond to pronunciation (irregular words) and for known words, whereas the former route would be used for unknown words and nonwords.

Such positions with regard to opaque languages have been based mainly on the study of reading ability, and have been related to general models that support the existence of differentiated routes of linguistic processing, depending on whether the word is known or unknown or if it is a nonword (see, Coltheart, 1987; Coltheart, Curtis, Atkins, \& Haller, 1993; Patterson \& Shewell, 1987). Following these models, the processing of spoken or written language begins with acoustic analysis (speech) or visual-orthographic analysis (written). This process is common to the processing of words and of nonwords, given that its function is to analyze the acoustic or visual quality, differentiating the sounds heard or the letters written, that is, extracting the individual phonemes or graphemes, and independently of nonlinguistic variables such as accent, tone of voice, handwriting, and so on.

Subsequently, the route for the reproduction of known words is that which we could call the semantic route. In this route, once the acoustic or visual quality has been analyzed, the word is recognized as belonging to the hearer's auditory or orthographic input lexicon, and it is then given a meaning through the cognitive system, also called the semantic system. If it is felt necessary to emit a word, the information goes to the phonological or graphemic output lexicon, which permits the production of words. There is a second route for the processing words, called the direct route, which directly connects the auditory or orthographic input lexicon and the phonological or graphemic output lexicon, without passing through the semantic system. The existence of this route is demonstrated by our ability to pronounce and repeat words whose meaning we do not know (Bub, Cancelliere, \& Kertesz, 1985; Howard \& Franklin, 1987; Sartori, Masterson, \& Job, 1987). Lastly, a phonemic system would be responsible for setting in motion the neuromuscular mechanisms necessary for reading both words and nonwords.

Nonword analysis (acoustic or visual) is carried out with necessary phonological mediation, by means of an auditory to phonological (speech word) or orthographic to phonological (written word) conversion system, where the correspondence between the phoneme or grapheme and its phonology is established. Coltheart (1987) points out that the orthographic to phonological conversion system permits the joining of phonological representations by means of correspondence rules, which follow these steps: (a) acousticorthographic segmentation of the written or spoken sequence, (b) phonological assignment to each of the segments, and (c) joining (or blending) of the phonemes or graphemes in a sequence ready to be emitted (see also Coslett, 1991).

The possibility of a dual route in transparent languages, such as those proposed in opaque languages, has been the subject of some discussion. The existence of these routes in adults is empirically demonstrable by studying neurologically damaged patients who are capable of repeating, writing from dictation, or reading words, but are incapable of carrying out such activities with unknown words or nonwords (phonological dyslexia). One of the first descriptions of such a case was by De Bastiani, Barry, and Carreras (1998), who reported the case of the Italianspeaking patient A.M.M., with selective deficit in the reading of nonwords but without appreciable effects on psycholinguistic variables such as frequency, concreteness, and length, although grammatical aspects were affected, and a marked lexicalization effect was found. The authors explain A.M.M.'s residual reading ability by means of a visual-lexical strategy. In this same line, Cuetos, ValleArroyo, and Suárez (1996), studying the Spanish-speaking patient A.D., also found selective damage in the reading of nonwords. In this case no appreciable lexicalization effects were found, nor effects on frequency, concreteness, or grammatical class, and repetition was quite well preserved. Thus, A.D.'s problem was attributed to the subprocess of phonetic blending, which forms part of the functions attributed to the orthographic to phonological conversion system, used in the nonlexical route, but which leaves lexical processing intact. Similar cases have subsequently been described in Spanish-speaking patients (see, for example, Dansilio \& Dalmas 1997; Cuetos \& Labos, 2001; Cuetos, Martínez, Martínez, Izura, \& Ellis, 2003; Ferreres, López, \& China, 2002; Ferreres, Martínez-Cuitiño, Jacubovich, Olmedo, \& López, 2003; Iribarren, Jarema, \& Lecours, 1999).

In addition to these cases diagnosed as phonological dyslexia, complementary cases have been described in which patients presented difficulties in reading words while nonword reading was conserved (deep dyslexia, Cuetos y Labos, 2001; Ferreres, Martinez-Cuitiño, \& Olmedo, 2005; Ruiz, Ansaldo, \& Lecours, 1992). Also, as in opaque languages, there have been descriptions of cases diagnoses as surface dyslexia, in which the reading of words and nonwords is conserved, but the patient has problems with irregular words (homophones, pseudohomophones, and foreign words; Iribarren, Jarema, \& Lecours, 1996; Ferreres et al., 2005). 
This set of evidence suggests that the use of a dual route (lexical and nonlexical) is similar in opaque and transparent languages, and indicates a cognitive reading system of a universal nature. However, it is possible that reading strategies for words and nonwords share certain basic rules that form a functional network with distributed representations, as proposed by the so-called connectionist models (see Seidenberg \& McCleland, 1989). In this line, Seidenberg, Plaut, Petersen, McClelland, and McRae (1994) indicate the importance of weighted connections between basic units for reading, which could replace or complement the two naming mechanisms proposed by the dual route model.

In this work, we study a case that indicates the existence of these different routes for the processing of unknown words and nonwords. J.V.M. presents a selective disorder for the nonlexical processing of written verbal stimuli that results in a severe incapacity for the reading of nonwords, with a lexicalization effect, that is, the patient reads the nonwords as though they were words. By comparison, this patient's reading of words was significantly better than his reading of nonwords. In sum, the present study confirms the results of the few previous studies with transparent languages that suggest the existence of various routes in reading. Nevertheless, in the Discussion, we also consider the possibility that the results can be explained, at least partly, by the use of shared strategies for the reading of words and nonwords, as proposed by connectionist models.

\section{Case Report}

J.V.M. is a right-handed male, 46 years old, and with an elementary level of education. According to his clinical history, he suffered craneoencephalic trauma, causing right hemiparesis and aphasia. The neurological report carried out by means of CT scan shows: hypo-dense image in the left temporal-parietal region.

\section{Neuropsychological Assessment}

J.V.M. was assessed in a total of 10 sessions, two per week, of approximately one hour's duration. The neuropsychological assessment showed J.V.M. to have an IQ of 93, according to the Wechsler Adults Intelligence Scale (WAIS; Wechsler, 1955), with no differences between the verbal and manipulative areas (Verbal Quotient $=90$, Performance Quotient =91). Memory assessment showed an MG of 93, according to the Wechsler Memory Scale (WMS; Wechsler, 1945). Assessment of visual and auditory perception and praxis with the Barcelona Test (Peña Casanova, 1990) showed normal performance in all the tasks.

The formal assessment of language, carried out with the Boston Diagnostic of aphasia examination (BDAE) (Kaplan, Goodglass, \& Weintraub, 1978), in the form of the Spanish adaptation by García Albea, Sánchez Bernardos and del
Viso (1986), showed fluent spontaneous speech, with normal grammatical construction and no articulatory difficulties (percentile 80). However, speed of production was somewhat slower than normal. Repetition was another linguistic parameter that appeared to be preserved, both for words and for phrases (percentile 90). We administered a repetition test of 20 nonwords, which he performed correctly (90\% of correct answers). Ability in naming from visual presentation was relatively acceptable (percentile 70), as was comprehension of spoken language (percentile 70). Comprehension of written language, on the other hand, was seen to be impaired, as was reading ability (percentiles 20 and 30, respectively). Lastly, writing ability was totally absent, apart from copying. In sum, the formal assessment of J.V.M. demonstrated his problems in reading tasks, with multiple errors, and a total lack of writing ability.

From these results, we carried out a specific assessment of the processing of written language, with the aim of determining the nature of this patient's disorder. All the tasks designed were previously administered to a 20-subject control group with similar age and educational level as J.V.M. The control group correctly performed all the tasks (100\% correct responses, except in the lexical decision task and in the separation of written items task, where there were $10 \%$ errors)

\section{Exploration of Written Word Processing}

Identifying and pairing letters and words. These tasks were designed to assess the visual-orthographic analysis. It is supposed that this system identifies each word, independently of the type of handwriting, by means of abstract identification of letter systems. The steps involved in this process are as follows: first, each letter is identified, regardless of the type of handwriting. Next, each letter is coded according to its position in the word, and last, the letters are grouped to form the word (Howard \& Franklin, 1987).

Identifying pairs of letters. This test consisted of presenting 24 pairs of letters, which could be the same ( $B$ - b) or different $(U-n)$. The patient had to indicate whether or not the letters were the same. J.V.M. completed this task without difficulty (100\% correct responses).

Pairing written items. This test consisted of pairing an item written on an individual card with the same word from a card bearing five written items. The length of words on the five-item card varied from 4 to 10 letters (20 of four letters, 20 of five letters, 20 of six letters, 20 of eight letters, and 20 of ten letters). Frequency of use of words was controlled by using similar numbers of words with high, medium, and low frequency (Juilland \& Chang Rodriguez, 1964). The task had two parts: In the first part, 20 trials with words were carried out, and in the second part, the 20 trials were with nonwords. The patient carried out the two parts of the test without difficulty (100\% correct responses). 


\section{Lexical Decision}

Continuing with the processing of the written word, the model predicts that after the visual analysis, there is a move to lexical routes through the system for the identification of written words (orthographic input lexicon). In order to assess this system, as well as its connections with the previous system (visual analysis), the following task was set. This task, designed to assess the functioning of the orthographic input lexicon, consisted of presenting the patient with a card bearing a word and a visually similar nonword (e.g., libro - "lißro" [book] tibro - "tißro"; controlled for frequency of use [words] and length). In 20 trials, the patient had to decide which one was the real word. J.V.M. completed the task with $80 \%$ (16/20) correct responses. Comparison of percentages between J.V.M. and the control group ( $90 \%$ of correct responses) did not show statistically significant differences. This result indicated that the system for identifying written words was relatively unimpaired.

\section{Comprehension}

This group of tasks was aimed at the assessment of the semantic route for reading, and included the following sections:

Separating written item task. This task consisted of separating into different piles 10 concrete words and 10 abstract words (controlled for frequency of use and length). The patient performed this task with $65 \%$ (13/20) correct responses, his errors being the inclusion of 4 abstract words in the concrete pile and 3 concrete words in the abstract pile.

Pyramid and Palm Test (written mode). This test was completed by J.V.M. with $63 \%$ (37/52) correct responses, which is a markedly poorer performance than that of a group of normal subjects of similar age and educational level, whose mean result was $90 \%$ (47/52) correct responses.

\section{Reading}

\section{Lexical route assessment.}

Reading words. A reading task was carried out using 60 words with high, medium, and low frequency of use (Juilland \& Chang Rodriguez, 1964). J.V.M. successfully read 58\% $(35 / 60)$ of the words. His errors are shown in Table 1. Classification of errors was carried out according to the proposals of Coltheart (1980), and are primarily of a visual nature, that is, the patient's response word is visually similar to the stimulus word, and the first syllable is identical. Also found, though to a lesser extent, were derivative-type errors, that is, the response word has the same separable morpheme as the stimulus word, and differs in the inseparable morpheme. Lastly, there were some semantic-type errors, that is, the response word belonged to the same semantic category as the stimulus word.

Reading concrete-abstract words. This task was designed to assess the concreteness effect in the word-reading tasks, and consisted of reading 30 words with concrete meanings and 30 with abstract meanings, all of them balanced in their frequency of use. For the first group, J.V.M. correctly read $53 \%(16 / 30)$ of the items, whereas only $10 \%(3 / 30)$ of the abstract words were read correctly. The difference between J.V.M.'s performance for the two groups of words was statistically significant, according to a difference of percentages test $(z=3.63, p<.01)$. For the abstract words, the patient responded with a word that was more concrete in $62 \%$ of the cases, as can be seen in Table 2. Types of error in both the abstract and the concrete word tasks were similar to those found in the word-reading task, that is, visual, derivative, and semantic.

Table 1

J.V.M.'s Word Reading Errors

\begin{tabular}{|c|c|c|}
\hline Type of errors & $\%$ of correct responses & Examples \\
\hline Visual & 47 & $\begin{array}{l}\text { puma-pluma [puma-pen] } \\
\text { puma-pluma }\end{array}$ \\
\hline Derivative & 11 & $\begin{array}{l}\text { sereno-serie [serene-series] } \\
\text { séreno-serie }\end{array}$ \\
\hline Semantic & 11 & 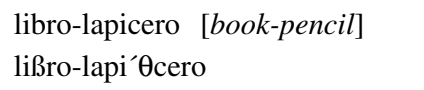 \\
\hline Other & 23 & $\begin{array}{l}\text { mechero-jersey [lighter-sweater] } \\
\text { me't } \text { fero -xer'sei }\end{array}$ \\
\hline
\end{tabular}

Note. Visual errors: patient's response bears visual similarity to the stimulus and shares the first syllable. Derivative errors: patient's response has the same separable morpheme and a different inseparable morpheme. Semantic errors: patient's response belongs to the same semantic category as the stimulus. 
Table 2

Concretion-Effect Response in the Task of Reading of Abstract Words Aloud

\begin{tabular}{|c|c|}
\hline Item - Translation - Pronunciation & Response - Translation - Pronunciation \\
\hline Poder [can $]$ po'der & Poner $[p u t]$ Póner \\
\hline Alegría [happiness] ale'gria & Elegir [choose] ele'xir \\
\hline Miedo [fear $]$ mi’eðo & Misa $[$ Mass $]$ 'misa \\
\hline Tristeza [sadness] tris`́te $\theta \mathrm{a}$ & Soltera $[$ spinster $]$ sol'tera \\
\hline Pena [grief] 'pena & Pana [corduroy] 'pana \\
\hline Belleza [beauty] be $\lambda \mathrm{e} \theta$ a & Pizarra [blackboard] piӨarra \\
\hline Grandeza [greatness] gran’de $\theta \mathrm{a}$ & Pantalla [screen] pan'ta $\lambda \mathrm{a}$ \\
\hline Reflexionar [reflect $]$ refleksion’ar & Enfriado [cooled $]$ enfríaðo \\
\hline Libertad [freedom] lißer'tað & Libreta [folder] li’breta \\
\hline Terror [terror] te'rror & Leer $[\mathrm{read}] \mathrm{le}^{\prime} \mathrm{er}$ \\
\hline Pereza [laziness] pe're $\theta \mathrm{a}$ & Pieza [piece] píe $\theta a$ \\
\hline Calidad [quality] kali’da $\partial$ & 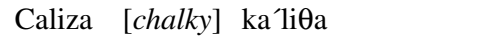 \\
\hline Remordimiento [remorse] remorðimi'ento & Reluciente $[$ shiny $]$ relu $\theta i e n t e$ \\
\hline
\end{tabular}

Reading different grammatical categories. J.V.M. was required to read 120 words (30 nouns, 30 adjectives, 30 verbs, and 30 function words). Results indicated $60 \%$ correct responses with nouns (18/30), 46\% with adjectives (14/30), $33 \%$ with verbs (10/30), and $80 \%$ with function words (24/30). Statistically significant differences were found between function words and all the other categories, and between nouns and verbs $(z=2.5 p<.05)$.

\section{Nonlexical Route Assessment}

Following the sequence of subprocesses included in the orthographic to phonological conversion system, the following tests were carried out:

Reading phonemes (sounds of individual letters). The patient had to indicate the sound of all the consonants in the Spanish alphabet (21). He obtained $72 \%$ correct responses $(15 / 21)$.

Reading syllables. The orthographic structures in the syllable reading task were consonant-vowel (CV) and VC. Percentage of correct responses was $65 \%(13 / 20)$.
Reading three- and four-phoneme syllables. The orthographic structures presented were CCV, CVC, CCVC. The patient answered correctly in only $30 \%$ of cases (10/30). The structure for which most correct responses were obtained was CVC, but no statistically significant differences were found.

Reading nonwords. The patient was asked to read 30 nonwords and was found to be totally incapable of responding correctly ( $0 \%$ correct responses). Moreover, he exhibited a lexicalization effect, that is, he responded with a word from his lexicon, and which bore a visual similarity to the stimulus, as can be seen in Table 3 .

Spelling words. J.V.M. was required to construct a word with a phonetic sequence (e.g., to spell aloud S-O-L and then pronounce the word sol [sun]). He responded correctly in only $10 \%$ of cases $(2 / 20)$. A similar task was designed with nonwords, but it was not possible to carry it out.

Another orthography task consisted in spelling words presented orally (e.g., the patient heard casa [house] and had to respond $\mathrm{C}-\mathrm{A}-\mathrm{S}-\mathrm{A})$. The patient responded correctly in only $5 \%$ of cases $(1 / 20)$.

Table 3

J.V.M.'s Nonword Reading Errors

\begin{tabular}{ll}
\hline Item - Pronunciation & Response - Translation - Pronunciation \\
\hline Deji' - dexi & Dibujo [rawing] - dißuxo \\
Mopu - 'mopu & Monja [nun] - 'monxa \\
Proen - 'proen & Empujen [push] - em'puxen \\
Bami - 'bami & maji [nonword] - 'maxi \\
Cadegi - kad'exi & Casado [married] - ka'saðo \\
Monpeca - mon'peca & Manteca [lard] - man'teka \\
Pituvo - pi'tußo & Puntero [pointer] - pun'tero \\
Morsuvu - mor'sußo & Mortifero [deadly] - mor'tifero \\
Ostuvo - os'tußo & Estudio [study] - es'tuðio
\end{tabular}




\section{Discussion}

The results of the cognitive assessment indicate that J.V.M. appears to carry out correctly the visual orthographic analysis of written language, as shown by his successful completion of the tasks of identification and pairing of written items. Likewise, J.V.M.'s performance in the lexical decision task indicates that he is able to recognize written words. On the other hand, he demonstrated his total incapacity for the reading of nonwords, which points to a functional absence of the nonlexical route, that is, the grapheme-phoneme conversion process. Moreover, J.V.M. is unable to perform phonological segmentation when more than two letters are involved. The direct lexical route was seen to be better preserved, and appears to be used by the patient, as demonstrated by the lexicalization effect in the reading of nonwords. However, although nonwords appear to be processed via this lexical route, its functionality is, at best, unstable, as evidenced by the presence of visual and derivative errors when reading words. Also, the lexicalsemantic route is not totally preserved in J.V.M., but maintains a degree of functionality, as indicated by the results of the comprehension tests and the concreteness effect in the reading of concrete and abstract words tasks.

The possibility of a prelexical deficit common to the two types of processing cannot be totally ruled out, given the mistakes in the reading of both words and nonwords. Our data point to a certain interconnection between the operations involved in reading known words and unknown or nonwords, which is compatible with connectionist models, such as those of Seidenberg and McClelland (1989). However, from our point of view, this approach also fails to explain fully the different performance in words and nonwords. More probably, J.V.M.'s performance could be explained by proposing, on the one hand, that there is some dysfunction in the interconnected network that generates operations or rules for reading all kinds of material and, on the other hand, that there is some partial dysfunction specifically affecting the route and operations preferentially used in nonlexical analysis. Hence, these results could be better interpreted from a perspective of compatibility or complementariness between certain standpoints of the connectionist and dual route models. This view has also been proposed by authors defending one approach or the other (see e.g., Coltheart et al., 1993; Seidenberg et al., 1994).

With regard to opaque and transparent languages for reading, this case study supports the existence of two routes in the (transparent) Spanish language, given the marked differences found between the reading of words and nonwords. However, as most Spanish words could be read via a nonlexical route, it can be assumed that the two routes are not totally independent, and that phonological correspondence rules are in some way influencing or imposing themselves upon the less-used lexical reading route.

This point of view is coherent with recent models of cerebral localization of language, which stress the interactive nature of brain circuits and the relationships between linguistic units of analysis (see, e.g., Damasio, 1992). The proposal of totally independent routes for linguistic processing is probably a simplification, bearing in mind the extensive organization of interconnections and neural networks that function in the brain, underlying cognitive processes. Thus, it is conceivable that cerebral lesions affecting mainly one of these functional routes or pathways of linguistic processing may also interfere to some extent in other reading or writing operations.

On the other hand, J.V.M.'s total inability to read nonwords is congruent with Coltheart's (1980) standpoint, with regard to the possible cerebral localization of the deficits. He points out that severe reading disorders could reflect massive damage in the left hemisphere, resulting in right hemisphere reading. J.V.M. presents extensive injury in the left parieto-temporal lobe, the consequence of a trauma, and his visual and semantic errors, as well as his strategies for reading (i.e., lexicalization effect), are congruent with this view.

\section{References}

Ardila, A. (1991). Errors resembling semantic paralexias in Spanishspeaking aphasics. Brain and Language, 41, 437-445.

Bub, D., Cancelliere, A., \& Kertesz, A. (1985), Whole-word and analytic translation of spelling to sound a nonsemantic reader. In K. Patterson, J.C. Marshall, \& M. Coltheart (Eds.), Surface dyslexia (pp. 15-34). London: Erlbaum.

Coltheart, M. (1980). The semantic error: Types and theories. In M. Coltheart, K. Patterson, \& J.C. Marshall (Eds.), Deep dyslexia (pp. 146-159). London: Routledge \& Kegan.

Coltheart, M. (1987). Functional architecture of the language processing system. In M.Coltheart, G. Sartori, \& R. Job (Eds.), The cognitive neuropsychology of language. (pp. 1-26). Hillsdale, NJ: Erlbaum.

Coltheart, M., Curtis, B., Atkins, P., \& Haller, M. (1993). Models of reading aloud: Dual route and parallel distributed processing approach. Psychological Review 100, 589-608.

Coslett, H.B. (1991). Read but not write "Idea": Evidence for a third reading mechanism. Brain and Language, 40, 425-443.

Cuetos, F., Valle-Arroyo, F., \& Suárez, M.P. (1996). A case of phonological dyslexia in Spanish. Cognitive Neuropsychology, 13, 1-24.

Cuetos, F., \& Labos, E. (2001). The autonomy of the orthographic pathway in a shallow language: Data from an aphasic patient. Aphasiology, 15, 333-342.

Cuetos, F., Martínez, T., Martínez, C., Izura, C., \& Ellis, A. (2003). Lexical processing in Spanish patients with probable Alzheimer's disease. Cognitive Brain Research, 17, 549-561.

Dansilio, S., \& Dalmás, F. (1997). Alexia fonológica (casi profunda) en castellano. Neuropsychología Latina, 2, 85.

Damasio, A. (1992), Aphasia. New England Journal of Medicine, $326,531-539$. 
De Bastiani, P., Barry, C., \& Carreras, M. (1998). Mechanisms for reading nonwords: Evidence from a case of phonological dyslexia in an Italian reader. In G. Denes, C. Semenza, \& P. Bisiacchi (Eds.), Perspectives in cognitive neuropsychology (pp. 253-267). Hove, UK: Erlbaum.

Ferreres, A., López, C., \& China, N. (2002). Phonological alexia with vowel-consonant dissociation in nonword reading. Brain and Language, 84, 399-413.

Ferreres, A., Martínez-Cuitiño, M., Jacubovich, S., Olmedo, A., \& López, C. (2003). Las alexias y los modelos de doble ruta de lectura en español. Revista Argentina de Neuropsicología, 1, 37-52.

Ferreres, A., Martínez-Cuitiño, M., \& Olmedo, A. (2005). Acquired surface alexia in Spanish: A case report. Behavioural Neurology, 16, 71-84.

Howard, D., \& Franklin, S. (1987). Three ways for understanding written words, and their use in two contrasting cases of "surface dyslexia.” In A. Allport, D.G. Mackay, W. Prinz, \& E. Sheerer (Eds.). Language perception and production: Shared mechanisms in listening, speaking, reading and writing (pp. 340-366). London: Academic Press.

Iribarren, I.C., Jarema, G., \& Lecours, A.R. (1996). The assessment of surface dyslexia in a regular orthography, Spanish: A case study. Brain and Cognition, 32, 196-198.

Iribarren, I.C., Jarema, G., \& Lecours, A.R. (1999). Lexical reading in Spanish: Two cases of phonological dyslexia. Applied psycholinguistics, 20, 407-428.

Juilland, A., \& Chang Rodriguez, E. (1964). Frequency Dictionary of Spanish Words. London: Mouton.

Kaplan, E. F., Goodglass, H., \& Weintraub, S. (1978). The Boston Naming Test. Philadelphia: Lea \& Febiger. (Spanish adaptation by García Albea, Sánchez Bernardos, \& del Viso. Test de Boston para el diagnóstico de la afasia. Madrid: MédicaPanamericana, 1986).

Patterson, K., \& Shewell, C. (1987). Speak and spell: Dissociation and word-class effects. In M. Coltheart, G. Sartori, \& R Job (Eds.), The cognitive neuropsychology of language (pp. 273292). London: Erlbaum.

Peña Casanova, J. (1990). Test Barcelona. Barcelona: Masson.

Ruiz, A., Ansaldo, A. \& Lecours, A.R. (1992). Two cases of deep dyslexia in unilingual Hispanophone aphasics. Brain and Language, 46, 245-256.

Sartori ,G., Masterson, J., \& Job, R. (1987). Direct-route reading and the locus of lexical decision. In M. Coltheart, K. Sartori, $\&$ R. Job (Eds.), The cognitive neuropsychology of language (pp. 59-76). London: Erlbaum.

Seidenberg, M.S., \& McClelland, J.L. (1989). A distributed, developmental model of word recognition and naming. Psychological Review, 96, 523-568.

Seidenberg, M.S., Plaut, DV., Petersen, A.S., McClelland, J.L., \& McRae, K. (1994). Nonword pronunciation and models of word recognition. Journal of Experimental Psychology: Human Perception and Performance, 20, 1177-1196.

Wechsler, D.A. (1945). Wechsler Memory Scale. New York: Psychological Corporation.

Wechsler, D.A. (1955). Wechsler Adult Intelligence Scale Manual. New York: Psychological Corporation.

Received November, 28, 2005

Revision received January, 23, 2007

Accepted September, 20, 2007 